\title{
International Conference on Chemistry and the Environment in Zurich
}

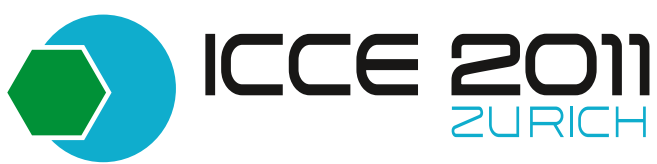

\author{
Walter Giger
}

Received: 5 June 2012 / Accepted: 12 June 2012 / Published online: 28 July 2012

(C) Springer-Verlag 2012

The journal Environmental Science and Pollution Research (ESPR) has a long history of co-operating with the EuCheMS Division of Chemistry and the Environment (DCE), and ESPR is the official organ of EuCheMS DCE (Giger 2010). In line with this joint venture, this special issue of ESPR reports on the International Conference on Chemistry and the Environment in Zurich-ICCE 2011 (Giger and Lubick 2012), the 13th biannual conference organised by EuCheMS DCE. In this special issue, ESPR publishes 10 articles that are based on presentations at ICCE 2011.

The year 2011 was of special importance for chemical science and technology because it was the United Nations International Year of Chemistry (IYC 2011). Many activities related to this special year featured past, current and future achievements of chemistry as a natural science discipline and as the basis for many products of modern civilization, including medical treatments. However, only a few IYC 2011 events evaluated and discussed the possibilities to lower negative impacts on humans and the environment caused by the chemical industry and by human-made chemicals. Exceptions were events that focused on sustainable chemistry and on energy issues. The ICCE 2011 aimed at somewhat alleviating the mentioned gap by emphasising the fate and effects of human-made chemicals in the environment.

Amidst all the celebrations of chemistry, the year 2011 also marked the 25th anniversaries of major chemical catastrophes in 1986: the nuclear calamity of Chernobyl and the major chemical spill into the Rhine River at Schweizerhalle. Furthermore, the year 2011 also saw its own nuclear disaster in Fukushima in Japan. Besides these drastic pulse releases of

Responsible editor: Philippe Garrigues

W. Giger $(\bowtie)$

GRC, Giger Research Consulting,

Im oberen Boden 128,

8049 Zurich, Switzerland

e-mail: giger@giger-research.ch chemicals into the environment, chronic environmental pollution by chemicals clearly continues to be very important.

The year 2011 also marked an important anniversary for an international activity that monitors long-term emissions and pollution: Ten years ago, the Stockholm Convention on Persistent Organic Pollutants was signed (Lammel and Lohmann 2012). Despite the treaty, these kinds of emissions continue, and consequently, there are good reasons for scientists and engineers to responsibly deal with and to devote much attention to the environmental aspects of chemistry.

The goal of ICCE 2011 was to provide a platform for information exchange for environmental scientists with a significant emphasis on chemistry. ICCE 2011 covered a broad range of areas of environmental chemistry, rather than focusing on a particular specific area (Giger and Lubick 2012).

The main goals of ICCE 2011 were:

- To link pioneering research with existing and upcoming environmental issues

- To bridge basic research and implementation activities

- To discuss the fate of chemicals in the environment

- To generate awareness for emerging contaminants

The ICCE 2011 followed with its concept and goals in the footsteps of the very successful ICCE 2009 held in Stockholm (de Lange et al. 2010). The ICCE 2009 gathered chemists to talk chemistry and share recent developments in chemistry within an environmental framework. With numerous international conferences, symposia and workshops dealing with environmental issues, the conveners decided that there was a need to establish an improved platform, an intimate meeting place for chemists active in environmental research. It was also felt that the size of the ICCEs, with approximately 500 attendees, ensures an optimum information exchange in contrast to much larger congresses and to quite smaller expert workshops. The next ICCE will be hosted on 25-28 June 2013 in Barcelona by the Catalan and Spanish Chemical Societies. 
This special issue of ESPR contains one review article and 9 original research papers contributed by authors from more than 10 countries. Samin and Janssen (2012) from the University of Groningen in The Netherlands present a critical review article on the transformation and biodegradation of 1,2,3-trichloropropane. Molnar et al. (2012) at the University of Novi Sad in Serbia studied the influence of $\mathrm{pH}$ and ozone dose on the content and structure of haloacetic acid precursors in groundwater. Teixidó et al. (2012) from the University of Barcelona in Spain looked into the sorption of tetracyclines onto natural soils. de Sousa Teixeira et al. (2012) from the University of Porto in Portugal investigated the removal of sulfamethoxazole from solution by walnut shells. Isobe et al. (2012) from the Ehime University in Japan surveyed the geographical distribution of nonPBDE-brominated flame retardants in mussels from Asian coastal waters. Yaçin et al. (2012) from the Istanbul University in Turkey characterised the biosorption of lead, cadmium and nickel in a species of marine brown macro algae. Rusu et al. (2012) of the Institute of Chemistry of the Academy of Sciences of Moldova together with Alfredo Alder from Eawag in Switzerland examined the dynamics of phosphorus forms in the bottom sediments and their interstitial water for the Prut River in Moldova. Two reports from Italy deal with particulate matter in the atmosphere: Amodio et al. (2012) at the University of Bari identified the origin of PM 10 exceedances and Masiol et al. (2012) of the University $\mathrm{Ca}^{\prime}$ Foscari in Venice used GC-MS analyses and chemometric processing to discriminate the local and long-distance sources of PAHs associated to atmospheric PM 2.5. Christiane Zarfl from the Leibniz Institute of Freshwater Ecology and Inland Fisheries with Zarfl et al. (2012) from the University of Osnabrück in Germany identified substances with potential for longrange transport as possible substances of very high concern.

\section{References}

Amodio M, Andriani E, de Gennaro G, Demarinis Loiotile A, Di Gilio A, Placentino MC (2012) An integrated approach to identify the origin of PM exceedances. Environ Sci Pollut Res. doi:10.1007/ s11356-012-0804-5

De Lange WT, Giger W, Bergman $\AA$ (2010) 12th EuCheMS International Conference on Chemistry and the Environment, Stockholm University, Stockholm, Sweden, 14-17 June, 2009. Environ Sci Pollut Res 17:1022-1023. doi:10.1007/s11356-010-0315-1

Giger W (2010) The EuCheMS Division of Chemistry and the Environment meets ESPR - a synergistic partnership. Environ Sci Pollut Res 17(4):817-819. doi:10.1007/s11356-010-0317-z

Giger W, Lubick N (2012) 13th EuCheMS International Conference on Chemistry and the Environment-ICCE 2011. Environ Sci Pollut Res, 19. doi:10.1007/s11356-012-0956-3

Isobe T, Ogawa SP, Ramu K, Sudaryanto A, Tanabe S (2012) Geographical distribution of non-PBDE-brominated flame retardants in mussels from Asian coastal waters. Environ Sci Pollut Res. doi:10.1007/s11356-012-0945-6

Lammel G, Lohmann R (2012) Identifying the research needs in the global assessment of toxic compounds 10 years after the signature of the Stockholm Convention. Environ Sci Pollut Res, 19. doi:10.1007/s11356-012-0967-0

Masiol M, Centanni E, Squizzato S, Hofer A, Pecorari E, Rampazzo G, Pavoni B (2012) GC-MS analyses and chemometric processing to discriminate the local and long-distance sources of PAHs associated to atmospheric PM2.5. Environ Sci Pollut Res. doi:10.1007/ s11356-012-0858-4

Molnar J, Agbaba J, Dalmacija B, Roncevic S, Prica M, Tubic A (2012) Influence of $\mathrm{pH}$ and ozone dose on the content and structure of haloacetic acid precursors in groundwater. Environ Sci Pollut Res. doi:10.1007/s11356-012-0896-y

Rusu V, Postolachi L, Povar I, Alder A, Lupascu T (2012) Dynamics of phosphorus forms in the bottom sediments and their interstitial water for the Prut River (Moldova). Environ Sci Pollut Res. doi:10.1007/s11356-012-0920-2

Samin G, Janssen DB (2012) Transformation and biodegradation of 1,2,3-trichloropropane (TCP). Environ Sci Pollut Res. doi:10.1007/s11356-012-0859-3

Teixidó M, Granados M, Prat MD, Beltrán JL (2012) Sorption of tetracyclines onto natural soils: data analysis and prediction. Environ Sci Pollut Res. doi:10.1007/s11356-012-0954-5

Teixeira S, Delerue-Matos C, Santos L (2012) Removal of sulfamethoxazole from solution by raw and chemically treated walnut shells. Environ Sci Pollut Res. doi:10.1007/s11356-012-0853-9

Yalçin S, Sezer S, Apak R (2012) Characterization and lead(II), cadmium(II), nickel(II) biosorption of dried marine brown macro algae Cystoseira barbata. Environ Sci Pollut Res. doi:10.1007/ s11356-012-0807-2

Zarfl C, Hotopp I, Kehrein N, Matthies M (2012 Identification of substances with potential for long-range transport as possible substances of very high concern. Environ Sci Pollut Res. doi:10.1007/s11356-012-1046-2

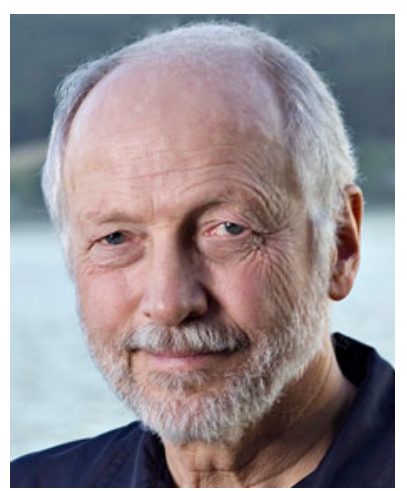

Walter Giger is a Scientist Emeritus at Eawag, the Swiss Federal Institute of Aquatic Science and Technology, and a Professor Emeritus at ETH Zurich, the Swiss Federal Institute of Technology. $\mathrm{He}$ is active as an Independent Consultant for Giger Research Consulting in Zurich. He is an expert on organic contaminants in the aquatic environment and in the evaluation of chemical, physical and biological processes determining the environmental fate of chemicals. Between 1990 and 2007 Dr Giger was Associate Editor of the journal Environmental Science and Technology published by the American Chemical Society. Since 2009, Dr Giger is chairing the Division of Chemistry and the Environment of the European Association of Chemical and Molecular Sciences (EuCheMS) and he is Consulting Editor of the journal Environmental Science and Pollution Research. Dr Giger has been appointed as an ISI Highly Cited Researcher in the field of Environmental Sciences. In 2008 the American Chemical Society named him a Legend of Environmental Chemistry, and the journal Environmental Science and Technology honored him with a Tribute Issue. 